\title{
Les lieux de l'Enfer dans les lettres françaises, a cura di Liana Nissim e Alessandra Preda
}

\section{Daniela Dalla Valle}

\section{(2) OpenEdition}

\section{Journals}

Edizione digitale

URL: http://journals.openedition.org/studifrancesi/792

DOI: 10.4000/studifrancesi.792

ISSN: 2421-5856

Editore

Rosenberg \& Sellier

\section{Edizione cartacea}

Data di pubblicazione: 1 agosto 2015

Paginazione: 359

ISSN: 0039-2944

\section{Notizia bibliografica digitale}

Daniela Dalla Valle, « Les lieux de l'Enfer dans les lettres françaises, a cura di Liana Nissim e Alessandra Preda », Studi Francesi [Online], 176 (LIX | II) | 2015, online dal 01 août 2015, consultato il 18 septembre 2020. URL : http://journals.openedition.org/studifrancesi/792 ; DOI : https://doi.org/10.4000/ studifrancesi.792

Questo documento è stato generato automaticamente il 18 settembre 2020.

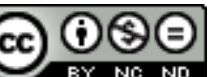

Studi Francesi è distribuita con Licenza Creative Commons Attribuzione - Non commerciale - Non opere derivate 4.0 Internazionale. 


\title{
Les lieux de l'Enfer dans les lettres françaises, a cura di Liana Nissim e Alessandra Preda
}

\author{
Daniela Dalla Valle
}

\section{NOTIZIA}

Les lieux de l'Enfer dans les lettres françaises. Convegno internazionale di studi, Gargnano 12-15 giugno 2013, a cura di Liana NISSIM e Alessandra PREDA, Milano, LED, 2014 («Studi secenteschi»), pp. 308.

1 L'ultimo convegno di Gargnano ha avuto come oggetto di studio 'I luoghi dell'Inferno' nella cultura francese, luoghi colti e analizzati sia a livello filosofico, sia-e soprattutto - a livello letterario. Il volume raccoglie gli Atti del Convegno, dove le comunicazioni sui testi studiati sono presentate in ordine cronologico: abbondanti quelle sul Cinquecento, e poi quelle sull'Ottocento e Novecento, mentre un solo testo è dedicato al Seicento: quello di Christian Biet che qui segnaliamo.

Prima, tuttavia, riteniamo utile segnalare la comunicazione di Michele MASTROIANNI (Un imaginaire infernal entre Bible et Baroque. La représentation de Satan et de l'Enfer dans le "Job" de Chassignet, pp. 87-107), perché l'uso del termine "barocco", esplicitato nel titolo, sembra avvicinare l'oggetto dell'articolo alle caratteristiche della cultura francese del primo Seicento. In realtà il Job di Chassignet ha come data 1592, e la comunicazione di Mastroianni sarà adeguatamente segnalata nella sezione Cinquecento della Rassegna. Tuttavia la presenza di una cultura che ha già molti elementi barocchi (forse manieristi?) caratteristici del poemetto di Chassignet, ci ha spinti a segnalare l'articolo anche nel settore secentesco.

Ritorniamo ora alla comunicazione di Christian BIET (Satan ment-il? La tragédie française, la politique et le diable au début du XVII siècle, pp. 109-125), l'unica che concerne il nostro secolo. Come il titolo della comunicazione suggerisce, l'attenzione dell'Autore si 
concentra sulle prime tragedie francesi del Seicento, anzi su un particolare settore di queste tragedie; Christian Biet ci fa entrare in questo campo, utilizzando i numerosi lavori svolti da lui stesso o sotto la sua direzione, ben noti a tutti i secentisti (come il volume dedicato al Théâtre de la cruauté et récits sanglants en France, Paris, Laffont, 2006); inoltre rinvia ad alcune tesi, ancora in fase di stampa e quindi non ancora conosciute, ma di cui è suggerito l'interesse (quella di Corinne Meyniel, quella di Charlotte Bouteille-Meister), rinviando anche ad altri studi-spesso recenti-utilizzati e qui riproposti ai lettori (ad esempio, quelli di Filippo D'Angelo).

Nella prima parte della comunicazione, Biet suggerisce gli elementi storici in cui il suo discorso letterario deve agglutinarsi: le guerre di religione, la conquista delle Indie, la Contro-Riforma, la sorcellerie...), evocati nel primo paragrafo, L'après-catastrophe, lieu de Satan; poi passa alla letteratura, per evidenziare come vi si manifesta la presenza di Satana (Présence réelle et présence fictionnelle du diable), infine si concentra sulle diverse forme in cui si può manifestare teatralmente satana, sia nelle manifestazioni cristiane, sia nella rievocazione dei testi classici (Furia, Megera, Spettro, Ombra). In particolare si sofferma sul contatto tra la presenza e la funzione di Satana e il regicidio (Satan instigateur de régicide); e da questo punto trae origine la seconda parte della comunicazione. Ora l'interesse dell'articolo si sposta dall'impostazione fornita dal quadro generale a un'attenzione più particolare, scegliendo come oggetto una particolare tragedia: La Tragédie sur la mort du roi Henri le Grand di Claude Billard (1610). Questa tragedia è letta e commentata soprattutto dal punto di vista della presenza drammaturgica di Satana, che da una parte determina alcune forme teatrali particolari (come il prologo fatto da Satana, che anticipa e spiega lo svolgimento dell'azione successiva) e dall'altra dal senso del contatto Satana/regicidio, esplicitato attraverso lo svolgimento dell'azione (sono i paragrafi 5, 6 e 7: Satan ouvre le bal, La vengeance de Satan, Les fureurs $d u$ Parricide). La comunicazione si conclude poi con una riapertura del discorso verso la storia e la tragedia del tempo, con il paragrafo 8: Comment arrêter la prophétie satanique? 